Revista de la Escuela de Ciencias de la Educación, año 14, nRo. 13, vol. 1, enero a junio de 2018. Páginas 65-84. ISSN 1851-6297 (DESDE DICIEMBRE DE 2006 A DICIEMBRE DE 2017). ISSN 2362-3349 (EN LiNEA). Evaluación DE COMPRENSIÓN LECTORA Y LIBRO ÁlBUM EN ESTUDIANTES DE FORMACIÓN INICIAL DOCENTE. ANA CAROLINA MALDONADO FUENTE, Pedro Rodrigo Sandoval Rubilar y Francisco Enrique Rodriguez Alveal.

\title{
EVALUACIÓN DE COMPRENSIÓN LECTORA Y LIBRO ÁLBUM EN ESTUDIANTES DE FORMACIÓN INICIAL DOCENTE
}

\author{
Por Ana Carolina Maldonado Fuentes* \\ Universidad de Bío-Bío, Chile. \\ amaldonado@ubiobio.cl \\ Pedro Rodrigo Sandoval Rubilar* \\ Universidad de Bío-Bío, Chile. \\ psandoval@ubiobio.cl \\ Francisco Enrique Rodríguez Alveal ${ }^{* * *}$ \\ Universidad de Bío-Bío, Chile. \\ frodriguez@ubiobio.cl
}

Recibido: 28/07/2017 Aceptado: 26/09/2017

* Es Profesora de Castellano (1993), Licenciada en Estética (1993) y Magíster en Ciencias de la Educación (1999). Profesora de lenguaje en el sistema escolar chileno (1995 a 2007), de español como lengua extranjera en la P. Universidad Católica de Chile (1997 a 2007) y de formación docente en la Universidad Academia de Humanismo Cristiano (UAHC) (2004 a 2007). Académica en la Universidad del Bío-Bío desde 2008 a la fecha. Jefa de la Unidad de Gestión Curricular y Monitoreo de la Universidad del Bío-Bío (20102014). Líneas de investigación: Formación Inicial Docente, Evaluación de Aprendizaje y Comprensión Lectora. Co-investigador del proyecto Grupo de Investigación en Educación (GIE) (Código GI-130823) de la Universidad del Bío-Bío.

* Es Doctor en Ciencias de la Educación. Académico, investigador y docente de Pregrado, Magíster y Doctorado en distintas universidades de Chile. Actualmente académico y representante de Posgrado de la Facultad de Educación y Humanidades en el Comité de Postgrado de la Universidad del Bío-Bío. Coordinado del Grupo de Investigación en Educación GIE (UBB código GI-130823), presidente Red de Investigadores Noveles en Investigación Educativa (rinie.cl), autor y coautor de múltiples publicaciones indexadas. El área de especialización e investigación desarrolladas son en el ámbito del currículo, evaluación curricular, de los Aprendizajes y Formación Inicial Docente.

*** Es Profesor de Estado en Matemática (1991), Magister en Bioestadística (1996). Académico en distintas universidades (Universidad de Concepción, Universidad de Chile, Universidad Católica de Temuco, Universidad Mayor) y de la Universidad del Bío-Bío desde el 2008 a la fecha. Líneas de investigación: Formación Inicial Docente, Teoría de Distribuciones y didáctica de la Estadística. 
Revista de la Escuela de Ciencias de la Educación, año 14, nRo. 13, vol. 1, enero a junio de 2018. Páginas 65-84.

ISSN 1851-6297 (DESDE DICIEMBRE DE 2006 A DICIEMBRE DE 2017). ISSN 2362-3349 (EN LíNEA). EVALUACIÓN DE COMPRENSIÓN LECTORA Y LIBRO ÁlBUM EN ESTUDIANTES DE FORMACIÓN INICIAL DOCENTE. ANA CAROLINA MALDONADO FUENTE, Pedro Rodrigo Sandoval Rubilar y Francisco Enrique Rodriguez Alveal.

\title{
Resumen
}

El propósito de la presente investigación es dar cuenta de la evaluación de la comprensión lectora en estudiantes de Formación Inicial Docente, cuyo dominio constituye uno de los aprendizajes claves del currículum escolar chileno. Específicamente, se aborda la lectura a partir de la información verbal (monomodal) y verbal-icónica (multimodal) en un libro álbum, siguiendo el modelo interactivo de lectura. En el marco de un diseño cuantitativo complementado de técnicas cualitativas, se aplicó un instrumento de lápiz y papel a 46 estudiantes de Pedagogía en Educación Parvularia y Pedagogía en Educación Básica de una universidad del centro sur del Consejo de Rectores de Chile. Los hallazgos, en general, evidencian resultados descendidos en las dimensiones evaluadas, cuyas diferencias son significativas entre los grupos de Formación Inicial Docente. Asimismo, se observan discrepancias en la calidad de las argumentaciones entre los estudiantes, lo que motiva a reflexionar respecto de qué tan preparados se encuentran los futuros profesores para la enseñanza de la comprensión lectora en el contexto de la multimodalidad, por lo que se invita a una revisión de los modelos formativos en este ámbito.

Palabras clave: Evaluación de Aprendizaje - Formación Inicial Docente Comprensión Lectora - Texto Multimodal - Libro álbum.

\begin{abstract}
The purpose of the present research is to evaluate the reading comprehension in students of initial teacher education, whose mastery is one of the key lessons learned in the Chilean school curriculum. Specifically, reading from verbal (monomodal) and verbal-iconic (multimodal) information is addressed in an album book, following the interactive reading model. In the framework of a quantitative design complemented by qualitative techniques, a pencil and paper instrument was applied to 46 pedagogy students of early childhood and primary education of a university in the south center of the Council of Rectors of Chile. The findings, in general, show lower results in the evaluated dimensions, whose differences are significant among the Initial Teacher Training groups. Likewise, there are discrepancies in the quality of arguments among students, which motivates us to reflect on how prepared future teachers are to teach reading comprehension in the context of multimodality. A review of training models in this area.
\end{abstract}

Keywords: Assessment for Learning - Initial Teacher Training - Reading Comprehension - Multimodal text - Picture Books. 
Revista de la Escuela de Ciencias de la Educación, año 14, nRo. 13, vol. 1, enero a junio de 2018. Páginas 65-84. ISSN 1851-6297 (DESDE DICIEMBRE DE 2006 A DICIEMBRE DE 2017). ISSN 2362-3349 (EN LíNEA). EVALUACIÓN DE COMPRENSIÓN LECTORA Y LIBRO ÁlBUM EN ESTUDIANTES DE FORMACIÓN INICIAL DOCENTE. ANA CAROLINA MaLdonAdo FUente, Pedro Rodrigo Sandoval Rubilar y Francisco Enrique Rodríguez Alveal.

\section{Introducción}

Desde la década de los 90, la Formación Inicial Docente (FID) ha sido un tema de interés para investigadores en educación (Sotomayor et. al, 2011; Reich, 2011; Pedraja-Rejas et al, 2012), dado que los docentes son un factor de alta incidencia en los resultados de los escolares. En este contexto, el Ministerio de Educación chileno (MINEDUC) ha buscado fortalecer políticas públicas para mejorar la formación de profesores y se han definido estándares orientadores de referencia nacional. En particular, se espera que un egresado de carreras FID, como profesional del siglo XXI, "esté preparado para enfrentar un entorno cambiante...(y) sea capaz de comunicarse por escrito y oralmente... (con) un comportamiento que refleje un nivel cultural adecuado a las exigencias de un mundo globalizado" (MINEDUC, 2011, p.15).

Sin embargo, evaluaciones en egresados de Formación Inicial Docente han dejado de manifiesto debilidades en los conocimientos disciplinares y pedagógicos de los estudiantes terminales de las carreras de Pedagogía en Educación Parvularia y Pedagogía en Educación Básica. En este caso, la formación disciplinaria se entiende como la especialización en un área determinada, siguiendo los contenidos del currículum escolar del nivel de enseñanza donde se desempeña el docente (Vezub, 2007, p.12). Específicamente en Lenguaje, foco central del presente estudio, los resultados del año 2011 evidencian que solamente el $52,7 \%$ de los evaluados alcanzan respuestas correctas en esta área, lo que preocupa y desafía fundamentalmente a las instituciones formadoras, pues es sabido que "mientras más amplio es el manejo pedagógico y disciplinar de un docente, mayores son las capacidades de incidir decisivamente en el proceso de aprendizaje de sus propios alumnos" (Bravo, Falk, González, Manzi, y Peirano, 2008; citado por Rodríguez y Castillo, 2014, p.5). No obstante estos resultados, estudios de percepción han evidenciado una alta concentración de valoraciones positivas asociadas a la formación didáctica y disciplinaria en lenguaje, según se trate de sujetos egresados de entidades selectivas o no selectivas (Ruffinelli, 2013).

Contar con antecedentes de esta naturaleza resulta de interés para la Formación Inicial Docente pues permite disponer de información sobre las habilidades adquiridas por los futuros profesores y su nivel de preparación para implementar el currículum escolar vigente en el aula. Asimismo, cobra relevancia en la trayectoria formativa, dado que evaluar conocimientos, capacidades y habilidades de los estudiantes en Educación Superior es un elemento crucial de la docencia (Brown, 2007). Investigaciones en esta línea, en general, han evidenciado que los estudiantes de pedagogía tienen habilidades descendidas en distintos ámbitos (Pedraja-Rejas et al, 2012), como en comprensión lectora (Maldonado, Sandoval y Rodríguez, 2012) y razonamiento matemático (Alveal y Rubilar, 2012). Específicamente, en relación con las habilidades de comprensión lectora, el contexto de la multimodalidad resulta un tema de interés inves- 
Revista de la Escuela de Ciencias de la Educación, año 14, nRo. 13, vol. 1, enero a junio de 2018. Páginas 65-84. ISSN 1851-6297 (DESDE DICIEMBRE DE 2006 A DICIEMBRE DE 2017). ISSN 2362-3349 (EN LíNEA). EVALUACIÓN DE COMPRENSIÓN LECTORA Y LIBRO ÁlBUM EN ESTUDIANTES DE FORMACIÓN INICIAL DOCENTE. ANA CAROLINA MALDONADO FUENTE, Pedro Rodrigo Sandoval Rubilar y Francisco Enrique Rodriguez Alveal.

tigativo, pues hoy en día los sujetos leen con "la utilización de muchos modos (distintos o unidos a la escritura) en objetos textuales variados" (Kress, 2005, citado en Barragán y Gómez, 2012, p. 85), siendo el código verbal uno de ellos.

En otras palabras, en la actualidad, el desarrollo de la habilidad de comprensión lectora atañe a nuevos textos multimodales, caracterizados por la existencia de diversas formas de codificar y crear significados a través de palabras, imágenes, sonidos, música y gestos. Lo anterior plantea un nuevo escenario para los docentes y los formadores de profesores, dado que los alumnos del sistema escolar se enfrentan a la comprensión de mensajes de diversa índole (libro álbum, infografías, presentaciones interactivas, páginas web, videojuegos), que exigen la consideración de múltiples saberes para el ejercicio de una lectura interpretativa. Asimismo, es posible constatar cómo la lectura de textos multimodales se incluye como parte de los contenidos disciplinares en los Estándares Orientadores para la Formación Inicial Docente (MINEDUC, 2011) y en el Marco Curricular vigente (MINEDUC, 2012). En particular, cabe señalar la incursión y la promoción del uso del libro álbum como una de las estrategias gubernamentales para el fomento lector en los primeros niveles del sistema escolar chileno (MINEDUC, 2006).

El contexto de la multimodalidad ha sido estudiado por Farías \& Araya (2014), teniendo como objeto de estudio a estudiantes de carreras pedagógicas. Los autores concluyen que "la formación inicial de profesores en especial en el área de Lenguaje no se ha hecho cargo de la incorporación del componente multimodal que interviene en los procesos de comprensión de lectura" (Farías y Araya, 2014, p. 298). Resulta de interés profundizar en este ámbito, dado que, al parecer, "los procesos de enseñanza aprendizaje de la comprensión de lectura aún permanecen ligados al texto articulado a través de la lengua, aunque los profesores reconocen la relevancia del texto multimodal en el paisaje semiótico actual" (Farías y Araya, 2014, pp.299-300). En otras palabras, "cuando se habla de procesos de lectura existe la tendencia a limitarlos a la interpretación de textos escritos" (Barragán y Gómez, 2012, pp. 82), asunto que no se condice con los actuales tipos lecturas disponibles, en que conviven las formas monomodal (texto) y multimodal (texto-imagen), entre otras.

A partir de las consideraciones anteriores y tomando en cuenta que para que los estudiantes del sistema escolar puedan desarrollar competencias "es preciso que el profesorado, a su vez, las tenga adquiridas, para poder ser mediador del proceso" (Comellas, 2000, p. 90) el presente estudio(1) tiene como propósito general: Evaluar la comprensión lectoraa partir de información presentada en forma monomodal y multimodal en un libro álbum,en estudiantes de Formación Inicial Docente de una universidad del Consejo de Rectores de Chile (2).

Para el logro de este propósito, se han definido los siguientes objetivos específicos: 
Revista de la Escuela de Ciencias de la Educación, año 14, nRo. 13, vol. 1, enero a junio de 2018. Páginas 65-84. ISSN 1851-6297 (DESDE DICIEMBRE DE 2006 A DICIEMBRE DE 2017). ISSN 2362-3349 (EN LíNEA). EVALUACIÓN DE COMPRENSIÓN LECTORA Y LIBRO ÁlBUM EN ESTUDIANTES DE FORMACIÓN INICIAL DOCENTE. ANA CAROLINA MaLdonAdo FUENTE, Pedro Rodrigo Sandoval Rubilar y Francisco Enrique Rodríguez Alveal.

1. Comparar la comprensión lectora a partir de información presentada en forma monomodal y multimodal en un libro álbum, en los estudiantes del grupo de estudio.

2. Correlacionar los porcentajes de logro promedio en comprensión lectora a partir de información presentada en forma monomodal y multimodal en un libro álbum.

3. Describir los argumentos explícitos entregados por los estudiantes para la comprensión lectora, a partir de información presentada en forma monomodal y multimodal en un libro álbum.

\section{Modelos de lectura y tipos de comprensión}

Teóricamente la lectura se ha explicado desde distintos modelos y enfoques, dando énfasis en determinadas destrezas o habilidades de procesamiento de la información. Por ejemplo, Cabrera, Donoso y Marín (1994) analizan la naturaleza de los procesos que se ponen en juego durante el aprendizaje de la lectura, aludiendo a la relación de interdependencia entre los componentes perceptivos, comprensivos y creativos. De ellos se destaca la comprensión como elemento esencial (más allá de la decodificación), conceptualizando la lectura como un proceso de tipo cognitivo y psicolingüístico, que es resultado de la combinación de una serie de habilidades específicas para la interpretación del texto.

Por otro lado, diversos autores (Alonso y del Mar Mateos, 1985; Medina et. al, 2009; Jiménez Pérez, 2014) hacen referencia al enfoque sintético (bottom up), que aconseja comenzar el proceso de comprensión por las palabras; el enfoque analítico (top down), que recomienda empezar dicho proceso por los aspectos más generales del texto; y, el modelo interactivo, entendido como la complementación del bottom up con el top down. El énfasis en los dos primeros enfoques ha explicado la lectura por largo tiempo, de lo cual se han derivado un conjunto de prácticas de enseñanza tradicionales. Por ejemplo, cuando se observa la importancia otorgada a las habilidades de decodificación, el reconocimiento global de palabras o la verificación de hipótesis a partir de lo que dice el texto.

Sin embargo, según Solé (2006) el modelo interactivo es uno de los modelos que explica en mejor forma el proceso, al comprender cómo el lector utiliza simultáneamente su conocimiento del mundo y su conocimiento del texto para construir una interpretación acerca de él. En razón de lo anterior, este último enfoque ha sido el más usado en los últimos años dado que coincide con una visión más holística del proceso lector. Las propuestas a nivel de enseñanza, en este caso, se basan en la necesidad de que los estudiantes aprendan a procesar el texto y sus distintos elementos, así como que manejen las distintas estrategias que hagan posible su comprensión. En otras palabras, en el modelo interactivo "se destaca la importancia del contexto que desencadena 
Revista de la Escuela de Ciencias de la Educación, año 14, nRo. 13, vol. 1, enero a junio de 2018. Páginas 65-84. ISSN 1851-6297 (DESDE DICIEMBRE DE 2006 A DICIEMBRE DE 2017). ISSN 2362-3349 (EN LíNEA). EVALUACIÓN DE COMPRENSIÓN LECTORA Y LIBRO ÁlBUM EN ESTUDIANTES DE FORMACIÓN INICIAL DOCENTE. ANA CAROLINA MALDONADO FUENTE, Pedro Rodrigo Sandoval Rubilar y Francisco Enrique Rodriguez Alveal.

la puesta en marcha de procesos específicos para la atribución de significados" (Viero, Peralbo\& García, 1997, p. 27).

De esta forma, la comprensión lectora corresponde a una habilidad compleja, por cuanto más allá de la decodificación lingüística del código verbal implica procesos de interpretación y construcción de sentido a partir de los conocimientos previos. Este conjunto de conocimientos incluye una variedad de experiencias y conceptos que le permiten al lector comprender e interpretar las ideas planteadas en el mensaje, a partir de fuentes de información ortográfica, gramatical, léxica, sintáctica, semántica y pragmática (Pinzás, 1995). Es decir, junto con hacer uso de los significados explícitos e implícitos, el lector es capaz de utilizarlos para deducir información y reorganizar los datos, estableciendo relaciones lógicas, reconociendo cuáles son los núcleos de significado más importantes, interpretando el mensaje y obteniendo una síntesis de su sentido. Cabe señalar que estas ideas se complementan desde una concepción sociocultural, en cuyo marco se asume la premisa que la construcción de significados y el conocimiento previo que aporta el lector tienen un origen social, por lo cual leer también constituye una práctica cultural (Cassany, 2006).

En síntesis, la comprensión lectora puede ser entendida como una habilidad básica para la alfabetización funcional dentro del sistema escolar, que se fundamenta en la capacidad del lector como sujeto hablante de una lengua para decodificar e interpretar significados, haciendo uso de sus conocimientos previos y de la información codificada en forma verbal, icónica o sonora en el texto. Se transforma así en una importante competencia discursiva, al permitir la interpretación de mensajes en función de distintos propósitos comunicativos y haciendo uso de diversas tipologías textuales, entre las cuales se encuentran los textos multimodales.

\section{La comprensión lectora en textos multimodales}

Tradicionalmente la comprensión lectora se ha centrado en la lengua escrita; sin embargo, con la expansión del acceso a la información, el auge de los medios de comunicación masivos y el amplio uso de las tecnologías e Internet, el énfasis radica en que los sujetos aprendan el uso de distintos modos para interpretar significados, siendo el código verbal uno de ellos. Es así como estudios recientes de alfabetismo funcional definen el dominio de lectoescritura como la identificación y conexión lógica entre enunciados y los conocimientos previos para la codificación y decodificación de la información (Lima, 2015). Se plantea así una nueva literacidad y tipología de textos (Martínez-Lirola, 2013), que exige la consideración de múltiples saberes para el ejercicio de una lectura interpretativa. Es decir, la multimodalidad puede ser entendida como "la utilización de muchos modos (distintos o unidos a la escritura) en objetos textuales variados" (Kress, 2005; citado en Barragán \& Gómez, 2012, p. 85). 
Revista de la Escuela de Ciencias de la Educación, año 14, nRo. 13, vol. 1, enero a junio de 2018. Páginas 65-84. ISSN 1851-6297 (DESDE DICIEMBRE DE 2006 A DICIEMBRE DE 2017). ISSN 2362-3349 (EN LíNEA). EVALUACIÓN DE COMPRENSIÓN LECTORA Y LIBRO ÁlBUM EN ESTUDIANTES DE FORMACIÓN INICIAL DOCENTE. ANA CAROLINA MALDONADO FUENTE, Pedro Rodrigo Sandoval Rubilar y Francisco Enrique Rodriguez Alveal.

Derivado de lo anterior hay un nuevo escenario en la educación, puesto que la comprensión de textos multimodales es parte de la cultura actual y, en consecuencia, lo es del currículo escolar. Surge así la necesidad de una redefinición del proceso de lectura y su aprendizaje, al integrar otras formas de codificación (visual, gestual, espacial) en la comprensión del sentido de un texto. Aun sabiendo que este proceso, tradicionalmente ha estado vinculado al predominio de la codificación lingüística y la linealidad de la información que se presenta de manera verbal. En otras palabras, se trata de transitar de una concepción sustentada con preferencia en la comunicación monomodal hacia una comunicación multimodal, que permita comprender mensajes constituidos por un ensamblaje de códigos, tal como sucede en el caso del libro álbum dentro de la literatura infantil.

Específicamente, el libro álbum se caracteriza por la doble codificación verbal-lingüística y visual-icónica. Esta forma de significación, supone la participación activa del lector tanto en la lectura literal como en la interpretación de la secuencia narratológica de las imágenes; puesto que "las imágenes no pueden ser entendidas sin los textos y los textos pierden sentido si se leen separadamente" (Hanán Díaz, 2007, p. 95). Es decir, los “álbumes" son textos que presentan una tensión dinámica entre verbalizaciones e ilustraciones, disponiendo simultáneamente de una serie de significantes y recursos propios de cada modo para que un lector pueda construir significados. Por lo anterior, el libro álbum es recomendado para afianzar la formación del lector literario en la escolarización básica, dada sus potencialidades para el desarrollo del pensamiento divergente y la creatividad en los primeros lectores. De allí que, "el álbum ilustrado se ha convertido actualmente en un objeto cultural de un notable potencial artístico, creativo y significativo en el universo de la literatura infantil y juvenil" (de Vicente-Yague Jara y Guerrero Ruiz, 2015, p. 401). Pese a lo anterior, tal como señala Villegas (2010, p. iii) "no hay evidencia demostrable de estudios cuantitativos o cualitativos sobre este tipo de textos en Chile exceptuando comentarios divulgativos" para su difusión.

Cabe señalar que dentro del marco teórico que da origen al presente artículo, se han planteado diversos enfoques de la lectura. En este caso, dado que se pretende abordar el proceso en textos multimodales de tipo libro álbum, se ha optado por concepciones más holísticas. Es así como se asume que la comprensión lectora corresponde a un proceso de interacción entre un lector activo y un texto, el cual está codificado y se puede decodificar desde la información presentada en forma verbal (monomodal) y en forma verbal-icónica (multimodal). Este proceso se caracteriza porque el lector va armando mentalmente una interpretación a partir de lo que se propone de manera explícita e implícita en la lectura y de los conocimientos previos. Por tanto, el sentido es construido por el lector a medida que va leyendo y va integrando información de las distintas fuentes (verbal, icónica, entre otras). 
Revista de la Escuela de Ciencias de la Educación, año 14, nRo. 13, vol. 1, enero a junio de 2018. Páginas 65-84. ISSN 1851-6297 (DESDE DICIEMBRE DE 2006 A DICIEMBRE DE 2017). ISSN 2362-3349 (EN LíNEA). EVALUACIÓN DE COMPRENSIÓN LECTORA Y LIBRO ÁlBUM EN ESTUDIANTES DE FORMACIÓN INICIAL DOCENTE. ANA CAROLINA MALDONADO FUENTE, Pedro Rodrigo Sandoval Rubilar y Francisco Enrique Rodriguez Alveal.

En concreto, resulta de interés explorar qué tan preparados se encuentran los futuros profesores para una lectura comprensiva de textos multimodales, considerando la codificación y decodificación monomodal y multimodalantes mencionada. En otras palabras, se trata de poder describir en mejor forma la capacidad de los sujetos para leer a partir de información verbal y de aquella cuyos referentes son el texto verbal y la imagen, en un libro álbum.

\section{Método}

\section{Diseño del Estudio}

Diseño de paradigma cuantitativo complementado con técnicas cualitativas. Dada la evaluación efectuada, en este caso se incorporan las verbalizaciones de los actores (argumentos explícitos en los reactivos de respuesta abierta) con el propósito de conferir mayor sentido a los datos numéricos; dado que "la utilización de los diseños de método mixto se constituyen, día a día, en una excelente alternativa para abordar temáticas de investigación en el campo educativo" (Pereira Pérez, 2011, p.15).

\section{Muestra}

Para efectos del estudio se realizó un muestreo estratificado, considerando una afijación proporcional al nivel de los estratos (estudiantes de Pedagogía en Educación Parvularia y Pedagogía en Educación Básica) con un error del $5 \%$ y un nivel de confianza del $95 \%$. El tamaño de la muestra mínimo es de 46 alumnos (Azorín y Sánchez, 1986). El 60,9\% se adscriben a la carrera de Pedagogía en Educación Parvularia y el 39,1\% a la carrera de Pedagogía en Educación Básica, siendo en su mayoría de género femenino (95,7\%). Cabe señalar que los estudiantes participaron en esta evaluación de manera informada y dieron su consentimiento, sabiendo que la medición tendría fines académicos de tipo diagnóstico, sin revelar datos personales ni resultados en forma individual.

\section{Instrumento}

En coherencia con los objetivos del estudio, se elaboró un instrumento de 11 preguntas del tipo de lápiz y papel (Himmel, Olivares y Zabalza, 1999, p.60), ad-hoc para la evaluación de la comprensión lectora a partir de información presentada en forma verbal (monomodal) y verbal-imagen (multimodal) en un libro álbum. El texto de lectura corresponde a los primeros nueve párrafos y cinco imágenes del libro álbum "La escoba de la viuda" de Van Allburg (1995), las que en su conjunto forman un núcleo temático cerrado. Este libro ha sido seleccionado por constituir un ejemplo bien logrado de la codificación dual (texto e imagen) (Hanán Díaz, 2007).

En la selección de técnicas de evaluación se tomó en consideración la propuesta de lbáñez (2012), incorporando preguntas de selección múltiple (se 
Revista de la Escuela de Ciencias de la Educación, año 14, nRo. 13, vol. 1, enero a junio de 2018. Páginas 65-84. ISSN 1851-6297 (DESDE DICIEMBRE DE 2006 A DICIEMBRE DE 2017). ISSN 2362-3349 (EN LíNEA). EVALUACIÓN DE COMPRENSIÓN LECTORA Y LIBRO ÁlBUM EN ESTUDIANTES DE FORMACIÓN INICIAL DOCENTE. ANA CAROLINA MALDONADO FUENTE, Pedro Rodrigo Sandoval Rubilar y Francisco Enrique Rodríguez Alveal.

presenta una serie de alternativas, entre las cuales se encuentra la correcta) y de redacción de respuesta abierta (se trata de una pregunta cuya respuesta debe proveer información específica o general obtenida a partir de la lectura). Estos reactivos se presentan alternados con fragmentos de texto e ilustraciones de "La escoba de la vida" (Van Allburg, 1995), sin alterar ni el orden ni la diagramación de los elementos constitutivos del álbum en la versión original. En otras palabras, hay preguntas que se presentan y contestan luego de la lectura de párrafos (información verbal; monomodal); y otras que se responden considerando en forma conjunta la información proveniente del texto verbal y la imagen (multimodal), los que se observan dentro de la misma página.

En el proceso de validación se analizaron las propiedades psicométricas del instrumento mediante el índice Alfa de Cronbach $(\alpha=0,60)$, valor considerado como "suficiente" en las primeras fases de una investigación (Nunnally, 1987). Además, se consideró el Kaiser, Meyer y Olkin (KMO), el cual arrojó un valor 0,48. La Tabla de Especificaciones se presenta a continuación.

\begin{tabular}{|l|c|}
\hline Fuente de codificación/decodificación & $\mathrm{N}^{\circ}$ preguntas \\
\hline Verbal (monomodal) & 7 \\
Verbal-Imagen (multimodal) & 11 \\
\hline TOTAL & \\
\hline
\end{tabular}

Tabla 1: Tabla de especificaciones del instrumento de comprensión lectora libro álbum

\section{Procesamiento de la información}

Dado que se trata de un estudio cuantitativo complementado con técnicas cualitativas, se hizo uso de resúmenes numéricos (promedio, porcentaje, desviación estándar, coeficiente de asimetría, mediana). En la comparación de los resultados promedios se utilizó la prueba t-Student y se estudiaron supuestos distribucionales para dar robustez a los hallazgos. Además se consideró el coeficiente de correlación lineal de Pearson para evidenciar la asociación entre las variables. En el caso de la codificación de respuestas abiertas, se procedió al análisis de contenido como procedimiento para categorizar los datos verbales obtenidos (Pérez Serrano, 2002). El procesamiento de la información cuantitativa fue realizado en el paquete estadístico SPSS 13.0 y la información cualitativa en el software Qualitative Data Analysis (QDA) de fuente libre.

\section{Resultados}

En primer lugar, se realizará un breve resumen del contenido del fragmento del libro álbum "La escoba de la viuda" (Van Allsburg, 1995) para contextualizar el análisis; y, en segundo lugar, se presentarán los resultados en función de cada uno de los objetivos específicos del estudio. 
Revista de la Escuela de Ciencias de la Educación, año 14, nRo. 13, vol. 1, enero a junio de 2018. Páginas 65-84. ISSN 1851-6297 (DESDE DICIEMBRE DE 2006 A DICIEMBRE DE 2017). ISSN 2362-3349 (EN LíNEA). EVALUACIÓN DE COMPRENSIÓN LECTORA Y LIBRO ÁlbUM EN ESTUDIANTES DE FORMACIÓN INICIAL DOCENTE. ANA CAROLINA MALDONADO FUENTE, Pedro Rodrigo Sandoval Rubilar y Francisco Enrique Rodriguez Alveal.

"La escoba de la viuda" (3) es contada por un narrador omnisciente en tercera persona que desde el inicio del cuento parte del supuesto que las brujas existen, tal como ocurre en los cuentos de hadas tradicionales. Sin embargo, la magia de sus escobas no es infinita y se agota, a diferencia de lo que sucede en otros relatos infantiles, con lo cual se plantea un quiebre con la ficción, dejando en evidencia una situación problema.

Un elemento importante a considerar en la codificación multimodal de este libro álbum es que las ilustraciones y los párrafos se presentan en formato vertical. Esto sirve para dar profundidad a los paisajes y a los espacios en que transcurre la historia. Las tonalidades utilizadas por el ilustrador tienen como base la gama de los colores sepia, fruto de lo cual se crea un paisaje invernal, fantástico yen cierta forma lúgubre. El personaje protagónico es la bruja, que luce vestida con una especie de bata, sombrero y zapatos puntiagudos.

El fragmento de la historia que se presenta en este caso, narra específicamente el episodio en que una bruja cae de manera imprevista en el huerto de legumbres de una viuda. Luego de recuperarse tras la acogida de la viuda en su casa, es recogida por otra bruja tras una llamada de auxilio que ella misma realiza en una fogata. Al principio, se incluye una ilustración que representa el viaje de la bruja, quien vuela detrás de los gansos. Después, a través del texto y dos ilustraciones se cuenta cómo la escoba de la bruja pierde sus poderes, en forma repentina, cayendo al suelo desde una altura considerable. Sigue la historia con el relato del encuentro de la viuda con la bruja en medio del huerto, quien, aunque está asustada, decide ayudar a la bruja malherida y le da asilo a la extraña mujer en su casa. La magia de la bruja le permite curarse rápidamente y logra salir antes del amanecer para hacer una fogata, con la cual logra llamar a sus amigas. Finalmente, se distingue el vuelo de una segunda bruja, quien aterriza junto al fuego y rescata a la primera bruja, emprendiendo vuelo y sobrevolando la copa de los árboles.

A continuación, se presentan los resultados derivados del estudio en función de los objetivos planteados. En coherencia el primer objetivo específico, se identifican los porcentajes de logro en comprensión lectora evidenciados por los estudiantes de ambas carreras bajo estudio, distinguiendo los resultados a partir de la información presentada en forma monomodal y multimodal en un libro álbum (Tabla 2).

\begin{tabular}{|l|c|c|c|}
\hline \multirow{2}{*}{ Tipo de información } & $\begin{array}{c}\text { Educación } \\
\text { Parvularia }\end{array}$ & $\begin{array}{c}\text { Educación } \\
\text { Básica }\end{array}$ & Valor-p \\
\cline { 2 - 4 } & $(\mathrm{n}=28)$ & $(\mathrm{n}=18)$ & \\
\hline Verbal (monomodal) & $68,0 \pm 12,3$ & $80,6 \pm 15,5$ & 0,003 \\
\hline Verbal-icónica (multimodal) & $62,8 \pm 16,6$ & $78,5 \pm 14,9$ & 0,002 \\
\hline
\end{tabular}

(Promedio \pm Desviación Estándar)

Tabla 2. Estadísticas básicas del logro promedio según grupo de estudio en relación a información monomodal y multimodal en un libro álbum. 
Revista de la Escuela de Ciencias de la Educación, año 14, nRo. 13, vol. 1, enero a junio de 2018. Páginas 65-84. ISSN 1851-6297 (DESDE DICIEMBRE DE 2006 A DICIEMBRE DE 2017). ISSN 2362-3349 (EN LíNEA). EVALUACIÓN DE COMPRENSIÓN LECTORA Y LIBRO ÁlBUM EN ESTUDIANTES DE FORMACIÓN INICIAL DOCENTE. ANA CAROLINA MALDONADO FUENTE, Pedro Rodrigo Sandoval Rubilar y Francisco Enrique Rodríguez Alveal.

La mayor frecuencia de logro porcentual promedio se observa cuando la información para la codificación/decodificación es de tipo verbal (monomodal) alcanzando valores de 80,6\% en Educación Básica y 68,0\% en Educación Parvularia. En este último caso el resultado es comparativamente más homogéneo, pues presenta la desviación estándar más pequeña. Estos resultados se derivan de aciertos en preguntas cuya formulación coincide con la visión tradicional de la lectura que pone énfasis en la presentación del contenido en forma monomodal (información verbal en párrafos), por sobre los logros si el contenido se presenta en forma verbal-icónica. Pese a lo anterior, los valores promedio en esta modalidad verbal no superan el $80,6 \%$ de logro, en el total de sujetos evaluados.

Por otra parte, al comparar los resultados por carrera, se observa que los estudiantes de Pedagogía en Educación Básica presentan porcentajes de logro menos descendidos en todas las dimensiones evaluadas; destacándose el $78,5 \%$ de logro promedio en la información verbal-icónica (multimodal), comparado con un 62,8\% logrado por los estudiantes de Pedagogía en Educación Parvularia en la misma categoría. En esta segunda dimensión evaluada, el acierto en las respuestas se vincula a la doble codificación, lo que suponía un elemento diferenciador respecto de la lectura tradicional, pues había que realizar la lectura interpretativa a partir de antecedentes proporcionados al mismo tiempo por los párrafos (información verbal) y la ilustración (información icónica).

Al respecto, cabe puntualizar que si bien existen diferencias estadísticamente significativas en los logros promedio, este estadístico no permite inferir sobre la distribución de los datos, motivo por el cual en la siguiente tabla se muestra el coeficiente de asimetría de Pearson. De esta forma, se contará con información respecto de la complejidad de las dimensiones evaluadas según grupo de estudio.

\begin{tabular}{|l|c|c|c|}
\hline \multirow{2}{*}{ Tipo de información } & $\begin{array}{c}\text { Educación } \\
\text { Parvularia }\end{array}$ & $\begin{array}{c}\text { Educación } \\
\text { Básica }\end{array}$ & Total \\
\cline { 2 - 4 } & $\mathrm{n}=28$ & $\mathrm{n}=18$ & \\
\hline Verbal (monomodal) & 0,3 & $-2,5$ & -0.6 \\
\hline $\begin{array}{l}\text { Verbal-Icónica } \\
\text { (multimodal) }\end{array}$ & 0,5 & $-0,2$ & 0.1 \\
\hline
\end{tabular}

Tabla 3. Coeficientes de asimetría según información monomodal y multimodal en un libro álbum.

Tal como se muestra en la tabla, es posible notar que en el grupo de Educación Parvularia se presenta una distribución asimétrica positiva $(C A>0)$ tanto en lo verbal (monomodal) como en lo verbal-icónico (multimodal). Se 
Revista de la Escuela de Ciencias de la Educación, año 14, nRo. 13, vol. 1, enero a junio de 2018. Páginas 65-84. ISSN 1851-6297 (DESDE DICIEMBRE DE 2006 A DICIEMBRE DE 2017). ISSN 2362-3349 (EN LíNEA). EVALUACIÓN DE COMPRENSIÓN LECTORA Y LIBRO ÁlbUM EN ESTUDIANTES DE FORMACIÓN INICIAL DOCENTE. ANA CAROLINA MALDONADO FUENTE, Pedro Rodrigo Sandoval Rubilar y Francisco Enrique Rodriguez Alveal.

evidencia que los estudiantes evaluados de esta carrera obtienen bajos porcentajes de logro en dichas modalidades; en cambio, en el grupo de Educación Básica la situación es diametralmente opuesta $(\mathrm{CA}<0)$, lo que indica que estos estudiantes tienden a tener porcentajes de logro menos descendidos en ambas dimensiones (monomodal y multimodal).

Otra medida de interés en el resumen de información numérica es el valor mediano, situación que se justifica aún más cuando la distribución de los datos es asimétrica. Como se observa en la siguiente tabla, los porcentajes de logro mediano en el grupo de Educación Parvularia son más descendidos que el grupo de Educación Básica en ambas modalidades. En particular en la dimensión verbal-icónica (multimodal) el cincuenta por ciento de los casos de Educación Parvularia presenta un logro promedio inferior al 57,0\%. Se evidencia que este conjunto de reactivos presentan un nivel de dificultad mayor para este grupo de estudiantes.

\begin{tabular}{|l|c|c|}
\hline \multirow{2}{*}{ Tipo de información } & Educación Parvularia & EducaciónBásica \\
\cline { 2 - 3 } & $(\mathrm{n}=28)$ & $(\mathrm{n}=18)$ \\
\hline Verbal (monomodal) & 70,0 & 80,0 \\
\hline Verbal-Icónica (multimodal) & 57,0 & 86,0 \\
\hline
\end{tabular}

Tabla 4: Porcentajes de logro mediano del grupo de estudio según información monomodal y multimodal en un libro álbum.

Por otro lado, en respuesta al segundo objetivo específico, cabe señalar que el instrumento de evaluación utilizado arroja una correlación estadísticamente significativa entre las dimensiones evaluadas $(r=0,54, p=0,000)$, en concordancia con la teoría del libro álbum, dado que una característica esencial en la construcción de este tipo de texto es la interacción entre los modos verbal-icónico (doble codificación).Lo anterior resulta relevante, toda vez que al no estar presente dicha cualidad se estaría en presencia de un libro con ilustraciones, puesto que "todos los álbumes son libros, pero no todos los libros son álbumes" (Durán 2000 citado en Isla Tirado, 2014, p.1). En otras palabras, a diferencia del uso decorativo de las ilustraciones en cuentos tradicionales, las imágenes en los libros álbumes juegan un papel fundamental por cuanto resultan imprescindibles para la decodificación e interpretación del mensaje, de forma que "debe prevalecer tal dependencia que los textos no puedan ser entendidos sin las imágenes y viceversa. Es decir, deben someterse a una interdependencia de códigos" (Hanán Díaz (2007, p.93)

Finalmente, en coherencia con el tercer propósito específico del estudio, se realiza una distinción más pormenorizada de las respuestas abiertas en los 
Revista de la Escuela de Ciencias de la Educación, año 14, nRo. 13, vol. 1, enero a junio de 2018. Páginas 65-84. ISSN 1851-6297 (DESDE DICIEMBRE DE 2006 A DICIEMBRE DE 2017). ISSN 2362-3349 (EN LiNEA). Evaluación DE COMPRENSIÓN LECTORA Y LIBRO ÁlBUM EN ESTUDIANTES DE FORMACIÓN INICIAL DOCENTE. ANA CAROLINA MaLdonAdo FUENTE, Pedro Rodrigo Sandoval Rubilar y Francisco Enrique Rodríguez Alveal.

reactivos de redacción, a fin de describir los argumentos explícitos entregados por los estudiantes para interpretar el cuento.

\begin{tabular}{|c|c|c|c|}
\hline \multirow{2}{*}{\multicolumn{2}{|c|}{$\begin{array}{l}\text { Ideas tipo (respuestas repetidas) } \\
(n=28)\end{array}$}} & $\begin{array}{l}\text { Educación } \\
\text { Parvularia }\end{array}$ & $\begin{array}{c}\text { Educación } \\
\text { Básica }\end{array}$ \\
\hline & & $(n=18)$ & \\
\hline \multirow{2}{*}{$\begin{array}{l}\text { Caída de } \\
\text { la bruja }\end{array}$} & Fue repentina/abrupta. & 93,9 & 100,0 \\
\hline & $\begin{array}{l}\text { No tuvo tiempo para reaccionar/ } \\
\text { cae de sopetón al suelo. }\end{array}$ & 21,4 & 72,2 \\
\hline \multirow{4}{*}{$\begin{array}{l}\text { Encuentro } \\
\text { de la bruja y } \\
\text { la viuda en } \\
\text { el huerto de } \\
\text { legumbres }\end{array}$} & $\begin{array}{l}\text { La viuda tenía miedo/temor/ } \\
\text { sintió miedo/estaba temerosa. }\end{array}$ & 94,6 & 100,0 \\
\hline & $\begin{array}{l}\text { La viuda estaba asombrada/ } \\
\text { se encontraba sorprendida/ se } \\
\text { aterroriza. }\end{array}$ & 46,6 & 77,7 \\
\hline & $\begin{array}{l}\text { La mano de la bruja sirve para } \\
\text { pedir ayuda/solicita ayuda } \\
\text { y auxilio/ señala dónde se } \\
\text { encontraba. }\end{array}$ & 92,9 & 94,4 \\
\hline & $\begin{array}{l}\text { La bruja no podía pedir ayuda } \\
\text { de otra manera/estaba en una } \\
\text { situación muy desvalida. }\end{array}$ & 50,0 & 66,6 \\
\hline \multirow{2}{*}{$\begin{array}{l}\text { Propósito de } \\
\text { la bruja al } \\
\text { rondar la casa }\end{array}$} & $\begin{array}{l}\text { Busca un elemento para llamar } \\
\text { a otra bruja/ pretende hacer } \\
\text { una señal y que la rescataran. }\end{array}$ & 47,3 & 52,6 \\
\hline & $\begin{array}{l}\text { Confirmar que no había nadie } \\
\text { más en la casa/Ver si corría } \\
\text { peligro en el lugar. }\end{array}$ & 25,0 & 44,4 \\
\hline \multirow{2}{*}{$\begin{array}{l}\text { Lo que hará la } \\
\text { bruja después } \\
\text { de emprender } \\
\text { vuelo }\end{array}$} & $\begin{array}{l}\text { Mandará a hacer una escoba } \\
\text { nueva/ va a buscar una nueva } \\
\text { escoba/conseguirá una nueva } \\
\text { escoba. }\end{array}$ & 94,4 & 96,4 \\
\hline & $\begin{array}{l}\text { Le contará al resto de las brujas } \\
\text { lo que le ocurrió/les contará su } \\
\text { anécdota a las demás brujas. }\end{array}$ & 42,8 & 88,8 \\
\hline
\end{tabular}

Tabla 5: Frecuencia porcentual de ideas tipo (argumentaciones) en preguntas de respuesta abierta según carrera.

Tal como se observa en la Tabla 5, se trabajó con un parámetro de "palabras" y/o "frase" como criterio de suficiencia para codificar cualitativamente 
Revista de la Escuela de Ciencias de la Educación, año 14, nRo. 13, vol. 1, enero a junio de 2018. Páginas 65-84. ISSN 1851-6297 (DESDE DICIEMBRE DE 2006 A DICIEMBRE DE 2017). ISSN 2362-3349 (EN LíNEA). EVALUACIÓN DE COMPRENSIÓN LECTORA Y LIBRO ÁlBUM EN ESTUDIANTES DE FORMACIÓN INICIAL DOCENTE. ANA CAROLINA MALDONADO FUENTE, Pedro Rodrigo Sandoval Rubilar y Francisco Enrique Rodriguez Alveal.

la presencia de ideas tipo (ideas que se repiten). Luego, a partir de esta codificación, se efectuó un análisis de frecuencia porcentual, considerando los casos observados. A continuación se resumen las ideas más frecuentes en las explicaciones que entregan los estudiantes.

Cabe señalar que la mayoría de los estudiantes plantea idea de que "la caída de la bruja fue repentina/abrupta", cuya referenciase encuentra presente en los primeros párrafos del texto (monomodal). Sin embargo, la frecuencia de casos disminuye cuando se añaden respuestas vinculadas al contexto de la situación, observando que la bruja "no tuvo tiempo para reaccionar", "cae de sopetón al suelo y no tuvo tiempo de sujetarse" o "trató de mover los brazos pero nada hizo posible que la caída fuera más ligera". Estas últimas acotaciones no se presentan explícitamente en la lectura del cuento, sino que se trata de ideas que pueden ser inferidas al relacionar la información verbal con la icónica (multimodal). En este caso, se observa una mayor frecuencia porcentual de respuestas en estudiantes de Pedagogía en Educación Básica, un $72,2 \%$, cuyo valor alcanza el 21,4\% en Pedagogía en Educación Parvularia.

En relación con las preguntas que apuntan a la interpretación del encuentro de la viuda con la bruja en el huerto de legumbres, la mayoría de los estudiantes evaluados argumenta en torno a la idea de que este personaje "tenía miedo", "sintió miedo", "tenía temor" o "estaba temerosa". Esta idea se expone en el texto y se deduce de la postura corporal del personaje en la imagen (modo icónico). Solamente algunos estudiantes complementan dicha interpretación con ideas del tipo "estaba asombrada" o "se encontraba sorprendida", añadiendo en la respuesta la expresión del rostro de la mujer que se infiere de la ilustración ("la viuda se aterroriza"). En este caso, la mayor frecuencia porcentual se observa en estudiantes de Pedagogía en Educación Básica (77,7\%). A nivel de detalles, más del $90,0 \%$ de los casos en ambas carreras de Formación Inicial Docente esgrime que la mano de la bruja se levanta para "pedir ayuda", "porque necesitaba ayuda" o "solicita ayuda y auxilio". Asimismo, un grupo de estudiantes aporta explicaciones adicionales integrando información global del texto y de la experiencia previa, con respuestas del tipo "no podía pedir ayuda de otra manera porque estaba magullada", "estaba en una situación muy desvalida" o "la caída fue muy fea por lo que señala dónde se encontraba".

Las ideas que se incluyen en las últimas dos filas de la Tabla 5 hacen referencia a preguntas sobre la última parte de la historia. Se trata del rescate de la bruja, quien logra encender una fogata en el patio del lugar donde se encuentra. Al consultar respecto del propósito de la bruja al rondar la casa la noche antes de este suceso, la mayor frecuencia porcentual se observa en torno a las ideas que ella "busca un elemento para llamar a otra bruja", "hace algo para que la fueran a buscar" o "pretende hacer una señal y que la rescataran", tomando como base la información global del texto, presentada en los 
Revista de la Escuela de Ciencias de la Educación, año 14, nRo. 13, vol. 1, enero a junio de 2018. Páginas 65-84. ISSN 1851-6297 (DESDE DICIEMBRE DE 2006 A DICIEMBRE DE 2017). ISSN 2362-3349 (EN LíNEA). EVALUACIÓN DE COMPRENSIÓN LECTORA Y LIBRO ÁlBUM EN ESTUDIANTES DE FORMACIÓN INICIAL DOCENTE. ANA CAROLINA Maldonado Fuente, Pedro Rodrigo Sandoval Rubilar y Francisco Enrique Rodríguez Alveal.

párrafos. En algunos casos, las ideas principales se complementan con otras que aluden a variados ámbitos, tales como "confirmar que no había nadie más en la casa", "ver si corría peligro en ese lugar" o "estudiar dónde se encontraba y no asustar a la viuda Shaw", cuyas respuestas corresponden principalmente a estudiantes de Educación Básica.

Finalmente, se consulta respecto de lo que pasará con la bruja protagonista después de emprender el vuelo. La mayoría de las respuestas coinciden con la idea de que "mandará a hacer una escoba nueva", "va a buscar una nueva escoba" o "conseguirá una nueva escoba". En algunos casos aislados se entregan frases alusivas a su confección. Cabe señalar que un $42,8 \%$ de los estudiantes de Pedagogía en Educación Parvularia y el 88,8\% de los estudiantes de Pedagogía en Educación Básica agregan información que no se encuentra explícitamente en el libro álbum. Estas ideas versan en torno a que la bruja "le contará al resto de las brujas lo que le ocurrió" o "les contará su anécdota a las demás brujas"; o bien, "dejará un regalo de agradecimiento" o "volverá a darle las gracias a la viuda". Un caso de excepción lo constituye la explicación "comprará una escoba con turbo que nunca perderá potencia", encontrándose también un ejemplo que afirma que la bruja "descansará después de lo ocurrido".

En general, el análisis de las respuestas abiertas permite inferir que los estudiantes de Formación Inicial Docente (FID) del grupo evaluado argumentan preferentemente desde antecedentes explícitos, considerando el sentido global del mensaje que se presenta en el libro álbum; con menor frecuencia porcentual de ideas fundamentadas en inferencias desde la información verbal-icónica (multimodal), lo que podría explicar las diferencias en el resultado final (Tabla 2). Esto permitió enriquecer el análisis de los resultados globales obtenidos a nivel de grupo, en que se observaron diferencias significativas entre las carreras, en las dimensiones monomodal (verbal) y multimodal (verbal-icónica).

\section{Discusión de Resultados}

Los antecedentes recogidos ponen de manifiesto que los sujetos del grupo de estudio alcanzan mayores porcentajes de logro promedio en la dimensión monomodal, respondiendo mejor frente a tareas de lectura cuando éstas se basan en la información verbal proporcionada en los párrafos del libro álbum.

Lo anterior es coincidente con la visión tradicional de la lectura, en la cual la codificación y decodificación del mensaje se basa principalmente en la información verbal del texto. Este tipo de lectura es posible de observar, por ejemplo, cuando en la enseñanza se privilegia la interpretación del sentido a partir de vocabulario y claves del texto, otorgando a las ilustraciones un papel de tipo decorativo. Esta práctica ha sido utilizada en la enseñanza escolar cuando se trabaja con libros ilustrados tradicionales, que se caracterizan por 
Revista de la Escuela de Ciencias de la Educación, año 14, nRo. 13, vol. 1, enero a junio de 2018. Páginas 65-84. ISSN 1851-6297 (DESDE DICIEMBRE DE 2006 A DICIEMBRE DE 2017). ISSN 2362-3349 (EN LíNEA). EVALUACIÓN DE COMPRENSIÓN LECTORA Y LIBRO ÁlBUM EN ESTUDIANTES DE FORMACIÓN INICIAL DOCENTE. ANA CAROLINA MALDONADO FUENTE, Pedro Rodrigo Sandoval Rubilar y Francisco Enrique Rodriguez Alveal.

no presentar una complementariedad de modos en su construcción. En este contexto, el libro álbum representa un nuevo género literario (Hanán Díaz, 2007) y como tal, invita a abordar la lectura y la educación literaria desde una perspectiva distinta a lo que se ha hecho durante décadas. En especial, dado que se trata de un tipo de texto que amplía la competencia comunicativa de los alumnos e implica aprendizajes vinculados a la lectura de imágenes y educación visual (Martínez, 2014).

Por otro lado, al momento de correlacionar las variables, se observa una relación significativa entre las dimensiones verbal y verbal-icónica. En otras palabras, ambos procesos están relacionados, en coherencia con la conceptualización del libro álbum. Asimismo, de estos resultados se desprende que los estudiantes con altos porcentajes de logro son capaces de responder correctamente la lectura basada tanto en la información verbal como en la codificación dual (multimodal); y, en caso contrario, quienes alcanzan resultados descendidos, lo hacen también en ambas dimensiones. La evaluación en este ámbito resulta de interés, dado que la lectura de libro álbum constituye una de las políticas vigentes para el fomento lector en los niveles de alfabetización inicial (MINEDUC, 2006). Por otra parte, el dominio de la codificación y decodificación en diversos modos constituye un aprendizaje esperado del ejercicio profesional docente, toda vez que la lectura multimodal ha sido incorporada como una de las orientaciones para la Formación Inicial Docente (MINEDUC, 2011).

En el análisis de las respuestas abiertas se observan ideas tipo que dan cuenta de la interpretación global del mensaje. En algunos casos, las respuestas evidencian vínculos con otros antecedentes derivados del texto (información verbal) y de la relación entre texto-imagen (información verbal-icónica). En general, los estudiantes de Formación Inicial Docente del grupo de estudio alcanzan frecuencias porcentuales más altas cuando sus argumentaciones se fundamenten en información de carácter monomodal. Este hallazgo resulta importante para la toma de decisiones respecto de qué tan preparados se encuentran para un alto desempeño en comprensión lectora, pues "la aproximación multimodal al libro álbum ha permitido comprender que no se lee solo el código verbal, sino que también se ve para leer, destacando la importancia del código visual para la construcción del significado" (Meneses, Ow y Unsworth, 2013, p.203).

\section{Conclusiones}

La lectura interpretativa de textos tipo libro álbum constituye uno de los aprendizajes esperados de la educación literaria infantil en la actualidad, valorándose positivamente tanto las características multimodales del género (estructura en una codificación verbal-icónica) y las potencialidades para la comprensión lectora.

De allí que "se hace necesaria una ampliación del concepto de lectura, pues la tradición científico-filosófica occidental y las prácticas educativas tra- 
Revista de la Escuela de Ciencias de la Educación, año 14, nRo. 13, vol. 1, enero a junio de 2018. Páginas 65-84. ISSN 1851-6297 (DESDE DICIEMBRE DE 2006 A DICIEMBRE DE 2017). ISSN 2362-3349 (EN LíNEA). EVALUACIÓN DE COMPRENSIÓN LECTORA Y LIBRO ÁlBUM EN ESTUDIANTES DE FORMACIÓN INICIAL DOCENTE. ANA CAROLINA MaLdonAdo FUENTE, Pedro Rodrigo Sandoval Rubilar y Francisco Enrique Rodríguez Alveal.

dicionales no contemplan la posibilidad de que las imágenes puedan ser abordadas como objetos de enseñanza y de aprendizaje orientados a desarrollar habilidades superiores de pensamiento" (Barragán y Gómez, 2012, p. 93).

En este contexto, la codificación y decodificación de información verbal-icónica resulta un ámbito de interés, en particular, dadas las actuales demandas para la Formación Inicial Docente (MINEDUC, 2006, 2011). En este caso, los resultados permitieron obtener antecedentes acerca de la evaluación de la comprensión lectora a partir de información monomodal y multimodal en estudiantes de Pedagogía en Educación Parvularia y Pedagogía en Educación Básica de una universidad del Consejo de Rectores, evidenciando diferencias significativas según carrera. Estos hallazgos podrían relacionarse con la formación recibida en la universidad, dado que todos los sujetos evaluados pertenecen a la misma población (4), igual cohorte de ingreso y cuentan con el mismo número de semestres académicos cursados.

Asimismo, invitan a reflexionar en torno a los modelos de enseñanza de la comprensión lectora durante la Formación Inicial Docente y la importancia de detectar necesidades de formación específicas vinculadas a la educación visual para la codificación multimodal (verbal e icónica). Lo anterior, dado que

"el pensar monomodalmente -como nos ha acostumbrado, en cierto sentido, a representarnos el mundo de la escuela- no permite razonar sobre las potencialidades comunicativas de cada modo semiótico, los efectos de sentido en el ensamblaje de estos modos para la construcción de un determinado mensaje y así experimentar los lenguajes, como repertorios de recursos disponibles, para alcanzar determinados objetivos de comunicación" (Meneses, Ow \& Unsworth, 2013, pp.202-203).

Al finalizar, cabe mencionar que los estudiantes que han sido objeto de estudio en este caso se han formado mayoritariamente en una sociedad postmoderna y se encuentran en etapas iniciales de su desarrollo profesional docente, por lo cual resulta de interés impulsar instancias de evaluación y monitoreo permanente de sus aprendizajes en torno a las dimensiones evaluadas, a fin de mejorar su desempeño. En especial, cobra relevancia crear instancias diversas para fortalecer sus logros en la comprensión lectora de textos multimodales, a través de propuestas curriculares que tributen al logro de los aprendizajes claves. Entre ellas, una alternativa puede ser la creación de actividades curriculares interdisciplinarias, con instancias de tipo taller, pensando en que "para que un maestro pueda conducir a sus estudiantes en la interpretación de textos visuales debe ser un consumidor crítico y activo de imágenes, un cinéfilo y, de ser posible, un creador" (Barragán y Gómez, 2012, p. 86). 
Revista de la Escuela de Ciencias de la Educación, año 14, nRo. 13, vol. 1, enero a junio de 2018. Páginas 65-84.

ISSN 1851-6297 (DESDE DICIEMBRE DE 2006 A DICIEMBRE DE 2017). ISSN 2362-3349 (EN LíNEA). EvaluaCIÓN DE

COMPRENSIÓN LECTORA Y LIBRO ÁlbUM EN ESTUDIANTES dE FORMACIÓn INICIAL DOCENTE. ANA CAROLINA Maldonado Fuente,

Pedro Rodrigo Sandoval Rubilar y Francisco Enrique Rodriguez Alveal.

\section{Notas bibliográficas}

(1) El artículo se enmarca en el desarrollo del Proyecto de Investigación en Docencia "El impacto de la evaluación formativa en el proceso de formación en estudiantes de Formación Inicial Docente (FID)" (Código 160123/DdoC).

(2) El Consejo de Rectores de las Universidades Chilenas ( $\mathrm{CRUCH}$ ) es una persona jurídica de derecho público, de administración autónoma, creado el 14 de agosto de 1954, (Ley № 11.575) como un organismo de coordinación de la labor universitaria de la nación. Está integrado por los Rectores de las veinticinco (25) universidades públicas y tradicionales del país.

(3) Existen blogs que proporcionan versiones resumidas de "La escoba de la viuda". En el presente estudio, las consultas se realizaron en: http://lacoleccionista-libroalbum.blogspot.cl/2013/11/la-escoba-de-la-viuda.html(Consultado el 11 de mayo de 2016); http://miscuentosinfantiless.blogpot.cl/2007/04/la-escoba-de-la-viuda-cuenta-cuentos.html (Consultado el 11 de mayo de 2016).

(4) Promedio Ponderado PSU para ingreso Educación Parvularia 558,7; Educación Básica 557,6; Notas de Enseñanza Media Educación Parvularia 5,9; Educación Básica 5,8; Caracterización Socioeconómica Q1,2,3 Educación Parvularia 83,3\%; Educación Básica 82,2\% (Fuente: DGAI, 2014).

\section{Referencias bibliográficas}

- Alonso, J. y del Mar Mateos, M. (1985). Comprensión lectora: modelos, entrenamiento y evaluación. Infancia y aprendizaje, 8, pp31-32, 5-19.

- Alveal, F. Rodríguez y Rubilar, P. Rodrigo Sandoval. (2012). Habilidades de codificación y descodificación de tablas y gráficos estadísticos: un estudio comparativo en profesores y alumnos de Pedagogía en Enseñanza Básica. Avaliação: Revista da Avaliação da Educação Superior (Campinas), 17(1), pp. 207-235.

- Ávalos, B. y Matus, A. (2010). La formación inicial docente en Chile desde una óptica internacional: Informe nacional del estudio internacional IEA TEDS-M. Santiago, Chile: Ministerio de Educación.

- Azorín, F. y Sánchez, J. L. (1986). Métodos y aplicaciones del muestreo. Madrid: Alianza.

- Barragán, R. y Gómez, W. (2012). El lenguaje de la imagen y el desarrollo de la actitud crítica en el Aula: propuesta didáctica para la lectura de signos visuales. Íkala, Revista de Lenguaje y Cultura, 17(1), pp. 81-94.

- Brown, S. (2007). Estrategias institucionales en evaluación. En Brown, S. y Glasner, A. (edit.) (2007). Evaluar en la universidad. Problemas y nuevos enfoques. Madrid: Narcea S.A.

- Cabrera, F., Donoso, T. \& Marín, M. (1994). El proceso lector y su evaluación. Barcelona: Laertes.

- Cassany, D. (2006). Leer tras las líneas. Sobre la lectura contemporánea. Barcelona: Ediciones Anagrama.

- Comellas, M. (2000). La formación competencial del profesorado: Formación continuada y nuevos retos organizativos. Revista Educar, 27, pp.87-101. Recuperado de http://www.raco.cat/index.php/Educar/article/view/20735/20575 
Revista de la Escuela de Ciencias de la Educación, año 14, nRo. 13, vol. 1, enero a junio de 2018. Páginas 65-84. ISSN 1851-6297 (DESDE DICIEMBRE DE 2006 A DICIEMBRE DE 2017). ISSN 2362-3349 (EN LínEA). Evaluación DE COMPRENSIÓN LECTORA Y LIBRO ÁLBUM EN ESTUDIANTES DE FORMACIÓN INICIAL DOCENTE. ANA CAROLINA MALDONADO FUENTE, Pedro Rodrigo Sandoval Rubilar y Francisco Enrique Rodriguez Alveal.

- De Vicente-Yague Jara, M.J. y Guerrero Ruiz, P. (2015). El cuento musical. Análisis de sus componentes textuales, musicales e ilustrados para el desarrollo de las competencias básicas en Educación Primaria. Profesorado. Revista de Curriculum y Formación del Profesorado. Vol. 19, (3) Septiembre-Diciembre 2015.

- Dirección General de Análisis Institucional (DGAI) (2014). Anuario estadístico institucional 2013. Universidad del Bío-Bío: Concepción.

- Farías, M. y Araya, C. (2014). Alfabetización visual crítica y educación en lengua materna: estrategias metacognitivas en la comprensión lectora de textos multimodales. Colombian Applied Linguistics Journal, 16(1), pp. 93-104.

- Hanán Díaz, F. (2007). Leer y mirar: el libro álbum. ¿Un género en construcción? Bogotá: Norma.

- Himmel, E.; Olivares. M. y Zabalza, J. (1999). Hacia una evaluación educativa. Aprender para evaluar y evaluar para aprender. Vol. I. Programa de Perfeccionamiento Fundamental. Santiago: Impresos Salazar.

- Ibáñez, R. (2012). La comprensión del discurso escrito: Una propuesta teóricometodológica para su evaluación. Revista Signos, 45(78), pp. 20-43.

- Isla Tirado, S. (2014). El álbum ilustrado y el cuento tradicional: En el Bosque de Anthony Browne. Tesis de Grado de Maestro en Educación Primaria. Universidad de Cantabria. Recuperado de: http://repositorio.unican.es/xmlui/handle/10902/5049

- Jiménez Pérez, E. (2014). Comprensión lectora vs Competencia lectora: qué son y qué relaciones existe entre ellas. Revista Investigaciones sobre Lectura, 1, pp. 65-74.

- Lima, A. M. (2015). INAF. Indicador de alfabetismo funcional. Reunión de expertos de América Latina y Caribe sobre alfabetización y educación de adultos. 26 y 27 de noviembre 2015, Montevideo, Uruguay. Recuperado el 11 de mayo de 2016 de http:// www.unesco.org/new/fileadmin/MULTIMEDIA/FIELD/Santiago/pdf/Ana-Maria-LimaDir-Instituto-Paulo-Montenegro-Brasil.pdf

- Maldonado Fuentes, A., Sandoval Rubilar, P. y RodriguezAlveal, F. (2012). Comprensión lectora en la formación inicial docente: estudiantes de educación general básica en una universidad del Consejo de Rectores. Revista Folios, (35), pp. 33-47.

- Martínez-Lirola, M. (2013). Experiencia de enseñanza multimodal en una clase de idiomas. Ensayos, Revista de la Facultad de Educación de Albacete, 28, pp. 1-13.

- Martínez, I. (2014). Conjunción del lenguaje literario y artístico en el aula de primaria a través del Álbum llustrado. Trabajo de fin de grado, Escuela de Educación de Soria, Universidad de Valladolid.

- Medina, A.; Gajardo, A. y Fundación Educacional Arauco (2009). Pruebas de Comprensión Lectora y Producción de Textos (CL-TP). Kínder a $4^{\circ}$ Año Básico. Santiago: Ediciones Universidad Católica de Chile.

- Meneses, A.; Ow, M. \& Unsworth, L. (2013). Alfabetización multimodal: múltiples textos, lectores y contextos. En Seminario Internacional ¿Qué leer? ¿Cómo leer? Perspectivas sobre lectura en la infancia. Programa Chile Lee, Ministerio de Educación, Santiago, Chile.

- MINEDUC (2006). Ver para leer. Acercándonos al libro álbum. Unidad de Currículum y Evaluación /Centro de Recursos para el Aprendizaje - CRA. Ministerio de Educación, República de Chile. Santiago: LOM. 
Revista de la Escuela de Ciencias de la Educación, año 14, nRo. 13, vol. 1, enero a junio de 2018. Páginas 65-84. ISSN 1851-6297 (DESDE DICIEMBRE DE 2006 A DICIEMBRE DE 2017). ISSN 2362-3349 (EN LíNEA). EvaluaCIÓN DE COMPRENSIÓN LECTORA Y LIBRO ÁlbUM EN ESTUDIANTES DE FORMACIÓN INICIAL DOCENTE. ANA CAROLINA MaLdonado Fuente, Pedro Rodrigo Sandoval Rubilar y Francisco Enrique Rodriguez Alveal.

- MINEDUC (2011). Estándares Orientadores para Egresados de Carreras de Pedagogía en Educación Básica. Santiago: LOM.

- MINEDUC (2012). Bases Curriculares para la Educación Básica. Decreto Supremo de Educación N439/2012. Santiago. Edición impresa 2013.

- Nunnally, J. (1987). Teoría psicométrica. México: Trillas.

- Pedraja-Rejas, L.; Araneda-Guirriman, C.; Rodríguez-Ponce, E. y Rodríguez-Ponce, J. (2012). Calidad en la Formación Inicial Docente: Evidencia Empírica en las Universidades Chilenas. Formación universitaria, 5(4), pp. 15-26.

- Pereira Pérez, Z. (2011). Los diseños de método mixto en la investigación en educación: Una experiencia concreta. Revista Electrónica Educare, pp. 15-29.

- Pérez Serrano, G. (2002). Investigación cualitativa. Retos e interrogantes. Volumen II. Técnicas y análisis de datos. En Pérez Serrano, G. (ed.). Capítulo IV. Método de análisis de contenido: origen y desarrollo. (3 ed.), pp.133-160. Madrid: La Muralla.

- Pinzás, J. (1995). Leer pensando. Serie de fundamentos de la lectura. Lima: Asociación de investigación aplicada y extensión pedagógica Sofía Pinzás.

- Reich, R. (2011). Convenios de Desempeño 2011-2014. Seminario SCT-Chile. Innovación y Armonización. Presentación del 31 de agosto de 2011.

- Rodríguez, C. \& Castillo, V. (2014). Calidad en la Formación Inicial Docente: los déficits de las competencias pedagógicas y disciplinares en chile. Revista Electrónica Actualidades Investigativas en Educación, 14, pp.1-25.

- Ruffinelli, A. (2013). La calidad de la formación inicial docente en Chile: la perspectiva de los profesores principiantes. Calidad en la Educación, (39), pp.117-154.

- Solé, I. (2006). Estrategias de lectura. Colección: Materiales para la Innovación Educativa (MIE).16ª edición. Barcelona: Graó.

- Sotomayor, C. et al (2011). La formación inicial de docentes de Educación General Básica en Chile. ¿Qué se espera que aprendan los futuros profesores en el área de Lenguaje y Comunicación? Revista Pensamiento Educativo. Revista de Investigación Educacional Latinoamericana. 48(1), pp. 28-41.

- Van Allburg, C. (1995). La escoba de la viuda. México: Fondo de Cultura Económica.

- Vieiro, P., Peralbo, M. \& García, J. (1997). Procesos de adquisición y producción de la lectoescritura. Madrid: Visor.

- Vezub, L. (2007). La formación y el desarrollo profesional docente frente a los nuevos desafíos de la escolaridad. Profesorado. Revista de Curriculum y Formación del Profesorado.

- Villegas, J. (2010). Aproximaciones a un estudio del libro-álbum narrativo: un caso práctico para la educación en valores en lectores adolescentes de Chile. (Tesis de Magíster). Disponible en: http://diposit.ub.edu/dspace/bitstream/2445/16063/1/ VILLEGAS_trabajofinaldeasterf.pdf 